\title{
Surface modifications of EVA copolymers induced by low pressure RF plasmas from different gases and their relation to adhesion properties
}

\author{
C. M. CEPEDA-JIMÉNEZ, R. TORREGROSA-MACIÁ \\ and J. M. MARTÍN-MARTÍNEZ* \\ Adhesion and Adhesives Laboratory, Department of Inorganic Chemistry, University of Alicante, \\ Apartado 99, 03080 Alicante, Spain
}

Received in final form 10 March 2003

\begin{abstract}
Two ethylene vinyl acetate (EVA) copolymers (12 and $20 \mathrm{wt} \%$ of vinyl acetate,VA, content) have been treated with low pressure RF plasmas from non-oxidizing gases $\left(\mathrm{Ar}, \mathrm{N}_{2}\right)$ and oxidizing gases (air, a mixture of $4 \mathrm{~N}_{2}: 6 \mathrm{O}_{2}(\mathrm{v} / \mathrm{v}), \mathrm{O}_{2}$ and $\mathrm{CO}_{2}$ ). The formation of polar moieties on both EVAs was more noticeable by treatment with plasmas from non-oxidizing gases than from oxidizing ones (the higher the reactivity, the lower the difference with respect to untreated EVA surfaces). The surface etching with the non-oxidizing plasmas, giving rise to a high roughness, depends on the wt $\%$ of VA in the composition of the copolymer because of the different resistances of VA (low) and PE (high) to the non-oxidizing plasma particles bombardment. The adhesion properties obtained using a polyurethane adhesive (PU) showed high T-peel strength values and adhesion failure in EVAs treated with plasmas from oxidizing gases, due to roughness produced causing mechanical interlocking of the adhesive. Lower T-peel strength values were obtained with non-oxidizing plasmas: the values for EVA12 being, in general, lower than those obtained for EVA20. The durability of the treated EVAs/PU adhesive joints after ageing in humidity and temperature was quite good.
\end{abstract}

Keywords: EVA; RF plasma treatment; surface chemistry; adhesion; contact angle measurements; XPS; scanning electron microscopy; T-peel strength.

\section{INTRODUCTION}

The great commercial importance of EVA copolymers is based on their desirable properties (high hardness, flexibility and transparency) obtained by the incorporation of vinyl acetate (VA) into the ethylene chain in the low density polyethylene (PE). Due to these properties, the EVA copolymers are used in the manufacture of

\footnotetext{
*To whom correspondence should be addressed. Phone: 34-96-5903977. Fax: 34-96-5903454. E-mail: JM.Martin@ua.es
} 
plastic laminates, cable wrapping, flexible pipes, soles in the footwear industry, and containers for food products. But EVA copolymers, like most polyolefins used in the industry, present serious incompatibilities with many adhesives, because of their low surface energy due to their non-polar nature.

To enhance the low compatibility of EVA copolymers with polar adhesives, several surface treatments have been proposed in order to give rise a higher surface energy, making the EVA surface more receptive to adhesive bonding.

Some surface treatments used in industry are physical in nature (brushing, roughening and solvent wiping) which act by removing abhesive substances on the surface or by improving interlocking with the adhesive. Thus, Wegman [1] proposed for EVA a treatment consisting of washing with methanol and immediate application of epoxy adhesive, followed by melting of the adhesive on the EVA surface at $100^{\circ} \mathrm{C}$ for $30 \mathrm{~min}$. In some cases, more aggressive chemical treatments are needed in order to modify the chemical composition of the surface of EVA, which result in a higher polarity and surface energy. However, the use of solvents is not recommended these days and cleaner methods have to be developed in the industry to meet the environmental regulations.

The industrial use of low pressure plasmas was developed in the sixties by the microelectronics industry for the deposition of thin films [2], and for the surface modification of semiconductors, metals and photoresist materials [3, 4]. Nowadays, the plasma treatment is also applied to non-polar polymeric surfaces to enhance their compatibility with polar substances, for instance, polyurethane implants with blood [5], or contact lenses with tears [6]. The extensive application of plasmas is due to their ability to enhance the adhesion properties of many materials, without altering the bulk properties [7].

The plasma state is considered the fourth state of matter, and is produced by applying an energy dose (in the range of radio frequencies, RF, in this study) high enough to produce ionization of the gas molecules yielding a mixture of electrons, particles with positive and negative charges, free radicals, atoms and molecules in excited states and UV radiation, as a result of the inelastic collisions between particles that exchange their energy [8]. A strong collision between the polymer chains at the surface and the particles and photons, generated during the RF discharge, takes place mainly via free radicals in the treatment of polymers with plasma.

It is known [8] that plasma produces four effects at the surface of materials. All of them are always present at the same time, although in different proportions, but one could prevail over the rest, depending on the substrate nature, plasma generation conditions and reactor design: (i) surface cleaning, consisting in the elimination of organic contaminants from the surface of materials; (ii) ablation or elimination of surface layers from the material; (iii) cross-linking between polymer molecules at the material surface, producing a denser structure at the surface than in the bulk; and (iv) modification of the chemical structure of the material surface. 
In this way, the effects produced by plasma in the materials are related to their surface properties. Because EVA copolymers are used in many industrial applications which require their adhesive bonding with other materials, the present study is devoted to the analysis of the surface treatment of EVA copolymers with low pressure RF plasma, and their adhesion properties in adhesive joints produced with polyurethane (PU) adhesive. There are a few papers [9-11] published dealing with the treatment of EVA copolymers with corona or plasma to improve their adhesion properties, but none of them considers the influence of the vinyl acetate content in the EVA on the effectiveness of the treatment. Therefore, this study contributes to the understanding of the effects of several low pressure RF plasmas on EVA copolymers with different vinyl acetate contents.

\section{EXPERIMENTAL}

\subsection{Materials}

2.1.1. Ethylene vinyl acetate (EVA) copolymers. Two EVA block copolymers containing 12 and $20 \mathrm{wt} \%$ of vinyl acetate (VA) from Repsol Química, S. A. (Santander, Spain) were used to fabricate rectangular specimens of size $150 \times$ $60 \times 2 \mathrm{~mm}$ by injection moulding in a Margarit JSW injection machine. Injection conditions were as follows: injection temperature, $200^{\circ} \mathrm{C}$; injection time, $6 \mathrm{~s}$; injection pressure as well as final pressure, $60 \%$ of the total pressure $\left(1570 \times 10^{5} \mathrm{~Pa}\right)$; injection using $70 \%$ of the total flow rate $\left(113 \mathrm{~cm}^{3} / \mathrm{s}\right)$; moulding temperature, $20^{\circ} \mathrm{C}$; and cooling time, $22 \mathrm{~s}$.

These EVA specimens, whose properties are given in Table 1, were cut into $150 \times 30 \times 2 \mathrm{~mm}$ pieces for surface treatment and subsequent characterization.

2.1.2. Adhesive. The polyurethane (PU) adhesive, made from thermoplastic PU Irostic P.9820 pellets from Morton (Osnabrück, Germany) was obtained by mixing $18 \mathrm{wt} \%$ PU pellets with 2-butanone, at 800 r.p.m. in a Oliver Batlle (Dispermix DL-M model) mechanical mixer, for $3 \mathrm{~h}$ at room temperature until a homogeneous solution of the adhesive was obtained. The viscosity of the adhesive solution was $2.0 \pm 0.2 \mathrm{~Pa}$, as determined in a Brookfield RTV viscosimeter at room temperature.

Table 1.

Some properties of EVA copolymers used in this study

\begin{tabular}{lllll}
\hline Copolymer & $\begin{array}{l}\text { VA } \\
(\mathrm{wt} \%)\end{array}$ & $\begin{array}{l}\mathrm{MFI}^{a} \\
(\mathrm{~g} / 10 \mathrm{~min})\end{array}$ & \multicolumn{2}{c}{ Hardness $^{\circ}$ Shore } \\
\hline EVA12 & 12 & 0.6 & $\mathrm{~A}$ & $\mathrm{D}$ \\
EVA 20 & 20 & 3.0 & 96 & 45 \\
\hline
\end{tabular}

${ }^{a}$ Melt flow index. 
Table 2.

Flow rate $(\mathrm{ml} / \mathrm{min})$ used to generate the low pressure RF plasmas with different gases

\begin{tabular}{lllllll}
\hline Gas & $\mathrm{Ar}$ & $\mathrm{N}_{2}$ & $\mathrm{Air}$ & $\left(4 \mathrm{~N}_{2}: 6 \mathrm{O}_{2}\right)$ & $\mathrm{O}_{2}$ & $\mathrm{CO}_{2}$ \\
\hline Flow rate $(\mathrm{ml} / \mathrm{min})$ & 57.7 & 45.9 & 31.7 & 43.3 & 33.2 & 41.6 \\
\hline
\end{tabular}

Table 3.

Wavelength (nm) and energy ( $\mathrm{kcal} / \mathrm{mol})$ of photons emitted by different gases ${ }^{a}$

\begin{tabular}{lllll}
\hline Gas & $\mathrm{Ar}$ & $\mathrm{N}_{2}$ & $\mathrm{O}_{2}$ & $\mathrm{CO}_{2}$ \\
\hline$\lambda(\mathrm{nm})$ & $334-529$ & 337 & $210-400$ & 10600 \\
\hline $\mathrm{E}(\mathrm{kcal} / \mathrm{mol})$ & $85-54$ & 85 & $135-71$ & 2.7 \\
\hline
\end{tabular}

${ }^{a}$ From National Institute of Standards and Technology, NIST, Atomic Spectra Database [12].

2.1.3. Low pressure RF plasma treatment apparatus. The low pressure RF plasmas were obtained using $\mathrm{N}_{2}, \mathrm{Ar}, \mathrm{O}_{2}, \mathrm{CO}_{2}$, air and a (v/v) mixture of $40 \% \mathrm{~N}_{2}+$ $60 \% \mathrm{O}_{2}$ (all gases being of purity higher than $99.990 \%$, provided by Abelló Linde S. A., Barcelona, Spain) in a March Plasmod Instrument (from Digit Concept, Mondeville, France) consisting of three modules: a Plasmod module containing the reaction chamber, a gas control module (GCM-200) for gas mixing, and an Edwards E2M8 vacuum pump.

The reaction chamber, a Pyrex barrel-like type, of $14 \mathrm{~cm}$ diameter is equipped with an aluminium perforated tray placed in the middle. The Plasmod module also contains an RF generator $(13.56 \mathrm{MHz})$ with variable power from 0 to $150 \mathrm{~W}$. The gas mixer has two flow controllers, one vacuum meter and a digital clock that allows to work in automatic mode.

All plasma surface treatments of the specimens were performed, in all cases, in manual mode. Four specimens (horizontally placed in the tray) were treated at the same time. The plasma chamber was evacuated to $1.995 \times 10^{-11} \mathrm{~Pa}$ and purged for 15 min with the gas used to produce the plasma. The gas pressure during plasma treatment was set to $1.33 \times 10^{-10}$ Pa before switching on the RF generator; the flow rate used for each gas is given in Table 2. The treatment time of samples by the RF Plasma ( $50 \mathrm{~W}$ power) was $5 \mathrm{~min}$. After treatment, the EVA samples were exposed to open air.

As mentioned previously, beside the particles produced in the plasma state, there is also emission of photons. The characteristics of the radiation emitted from the different gases used to obtain the low pressure RF plasmas radiation are given in Table 3, showing that the energy levels of the radiation emitted from non-oxidizing gases $-\mathrm{N}_{2}$ or $\mathrm{Ar}-$ are in the UV region, and for the oxidizing gases, $\mathrm{O}_{2}$, emits in this same UV region, whereas for $\mathrm{CO}_{2}$, the emission is in the IR region [12]. The energy level of UV radiation is enough to produce cross-linking of the PE chains (with monomer units of $-\mathrm{CH}_{2}-\mathrm{CHR}$ type), and scission of the VA chains (with monomer units of $-\mathrm{CH}_{2}-\mathrm{CRR}^{\prime}$ type) $[13,14]$. Therefore, when using plasmas 
from non-oxidizing gases, the etching process of the two EVA copolymers - by the UV radiation emitted - will give rise to different surface modifications depending on the proportions of the two monomers at the surface of copolymers. For the plasmas obtained with the more oxidizing gas, $\mathrm{O}_{2}$, the treatment results in strong ablation because of its high reactivity.

\subsection{Experimental techniques}

2.2.1. Thermogravimetric analysis. TG analysis curves were obtained on a Mettler TG 50, in order to determine the exact content of VA in the EVA copolymers. TG runs were made by using $8 \mathrm{mg}$ sample weight, placed in a ceramic crucible, submitted to a temperature programme consisting in heating from $30^{\circ} \mathrm{C}$ to $600^{\circ} \mathrm{C}$ at a heating rate of $5^{\circ} \mathrm{C} / \mathrm{min}$, under $\mathrm{N}_{2}(99.999 \%$ purity) at a flow rate of $300 \mathrm{ml} / \mathrm{min}$.

2.2.2. Differential scanning calorimetry. DSC experiments were carried out in a Rheometric Scientific DSC PLUS V calorimeter (software version 5.41). The specimens $(2-4 \mathrm{mg})$, placed in aluminium crucibles, were heated between $-100^{\circ} \mathrm{C}$ and $150^{\circ} \mathrm{C}$ (liquid $\mathrm{N}_{2}$ was used as a cryogenic bath), at a heating rate of $5^{\circ} \mathrm{C} / \mathrm{min}$ under $\mathrm{N}_{2}(99.999 \%$ purity) at a flow rate of $300 \mathrm{ml} / \mathrm{min}$. The thermal history of the samples was eliminated prior to all experiments by heating between $30^{\circ} \mathrm{C}$ and $150^{\circ} \mathrm{C}$ at $5^{\circ} \mathrm{C} / \mathrm{min}$, subsequent cooling down to $30^{\circ} \mathrm{C}$ within $30 \mathrm{~min}$ and reheating to $150^{\circ} \mathrm{C}$ at $5^{\circ} \mathrm{C} / \mathrm{min}$.

2.2.3. Contact angle measurements. Contact angles between EVA specimens and a test liquid (deionized and bidistilled water) were measured in a Ramé-Hart 100 goniometer. Before the measurements were performed at $25^{\circ} \mathrm{C}$, the goniometer chamber was allowed to saturate with the test liquid. Five different single drops $(4 \mu \mathrm{l})$ of the test liquid were deposited on the surface of the same EVA specimen and measurements were made $10 \mathrm{~min}$ after drop deposition, to give the average value of contact angle with an error less than \pm 2 degrees.

2.2.4. X-ray photoelectron spectroscopy (XPS). The XPS spectra of EVA specimens treated with plasma $(5 \mathrm{~mm} \times 2 \mathrm{~mm})$ were recorded in a V.G. Scientific Microtech Multilab spectrometer working at $15 \mathrm{keV}$ and $300 \mathrm{~W}$, the beam incidence angle being $45^{\circ}$. The specimens were outgassed in the vacuum chamber until the pressure was less than $6.66 \times 10^{-6} \mathrm{~Pa}$. Photoelectrons were obtained by X-ray irradiation from $\mathrm{Mg} K_{\alpha}(h v=1253.6 \mathrm{eV})$. The energy scale was calibrated using, as a reference, the energy of the $\mathrm{C} 1 \mathrm{~s}$ photopeak of hydrocarbon $(285.0 \mathrm{eV})$. In a first step, the XPS spectra were run in the energy range from 0 to $1100 \mathrm{eV}$ in order to determine the main elements existing at the surface of the EVA copolymers. After that, the high resolution XPS spectra were recorded in a narrower energy range $(20 \mathrm{eV})$ to determine the chemical state of each element. Atomic percentages of 
all elements were assessed by measuring the areas of individual peaks and applying the standard procedure to correct for the transmission function, photoemission cross section and photoelectron attenuation length. The chemical state of each element was established using the standard energy assignments found elsewhere [15].

2.2.5. Scanning electron microscopy (SEM). SEM pictures of the untreated and treated EVA surfaces, gold covered, were taken in a JEOL-840 Scanning Electron Microscope, using an energy of $20 \mathrm{kV}$ for the electron beam and a magnification of 500 .

2.2.6. T-peel strength tests. Immediately after plasma treatment, $1 \mathrm{ml}$ of PU adhesive solution was brushed on each specimen to be joined, the solvent allowed to dry for 20-30 min, and then the PU films were reactivated under an IR lamp at $80^{\circ} \mathrm{C}$ until melting. After that, the EVA surfaces, with the molten PU films on, were placed in contact under a pressure of $0.8 \mathrm{MPa}$ for $11 \mathrm{~s}$. The adhesive film was about $100 \mu \mathrm{m}$ thick. The adhesive joints of EVA materials were stored at $20^{\circ} \mathrm{C}$ and $50 \%$ relative humidity for $72 \mathrm{~h}$ before performing the T-peel strength tests in a universal test machine, Instron 4411 , with a clamp separation speed of $0.1 \mathrm{~m} / \mathrm{min}$. The error in the measurements was $\pm 0.5 \mathrm{kN} / \mathrm{m}$.

\section{RESULTS AND DISCUSSION}

\subsection{Characterization of EVA copolymers}

Table 4 shows the actual content of vinyl acetate in the EVAs obtained from the TG curves. The VA contents in the EVA copolymers were obtained taking into account that the first weight loss (WL\%) was due to the evolution of acetic acid from the decomposition of the vinyl acetate (VA) in the copolymer. The following equation was used to obtain the VA content in the EVAs:

$$
\mathrm{VA} \%=\mathrm{WL} \% \times\left(M_{\mathrm{m}} / M_{\mathrm{A}}\right)=\mathrm{WL} \% \times 1.4,
$$

where $M_{\mathrm{m}}$ is the molecular weight of the EVA monomer $\left(-\mathrm{CH}_{2}-\mathrm{CH}(\mathrm{OCO}-\right.$ $\left.\mathrm{CH}_{3}\right)-$ ), and $M_{\mathrm{A}}$ is that of acetic acid $\left(\mathrm{HOCO}-\mathrm{CH}_{3}\right)$. The VA contents given in Table 4 are in relatively good agreement with those provided by the manufacturer.

Table 4.

Actual composition of EVA copolymers (obtained from TG analysis)

\begin{tabular}{lll}
\hline Copolymer & VA $(w t \%)$ & PE $(w t \%)$ \\
\hline EVA12 & 13.3 & 86.7 \\
EVA20 & 20.6 & 79.4 \\
\hline
\end{tabular}




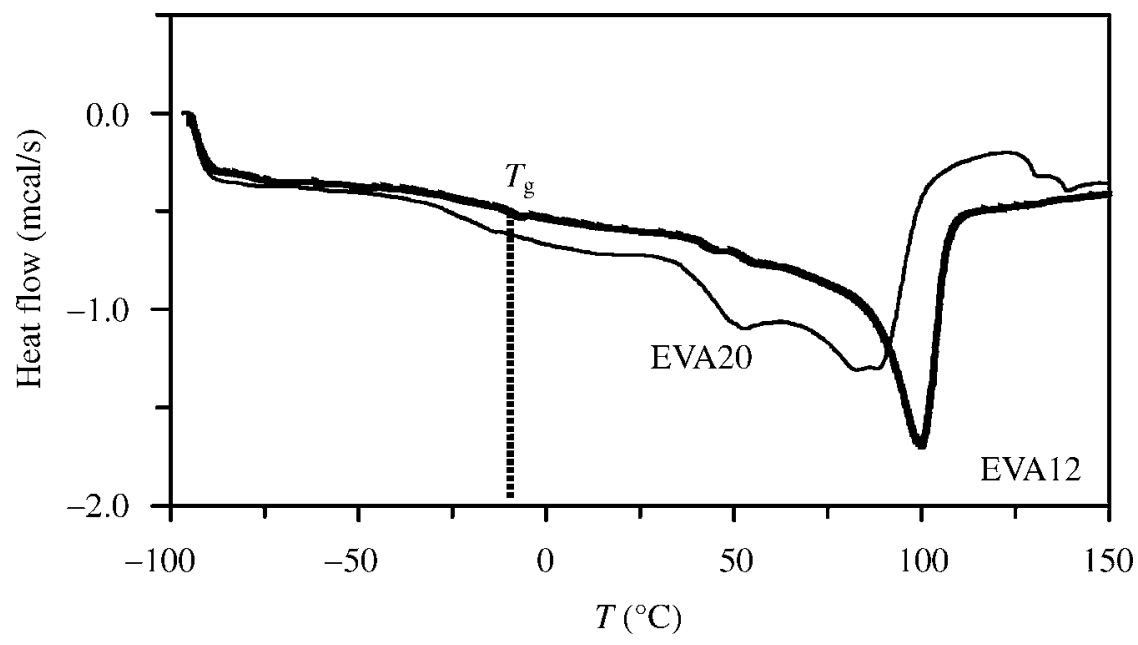

Figure 1. DSC thermograms for EVA12 and EVA20 copolymers.

Table 5.

Melting temperature $\left(T_{\mathrm{m}}\right)$, melting enthalpy $\left(\Delta H_{\mathrm{m}}\right)$ and glass transition temperature $\left(T_{\mathrm{g}}\right)$ of EVA copolymers obtained from DSC experiments

\begin{tabular}{llll}
\hline Copolymer & $T_{\mathrm{m}}\left({ }^{\circ} \mathrm{C}\right)$ & $\Delta H_{\mathrm{m}}(\mathrm{J} / \mathrm{g})$ & $T_{\mathrm{g}}\left({ }^{\circ} \mathrm{C}\right)$ \\
\hline EVA12 & 99 & 49 & -33 \\
EVA20 & $50,86.7$ & 24 & -31 \\
\hline
\end{tabular}

The glass transition temperature $\left(T_{\mathrm{g}}\right)$, the melting temperature $\left(T_{\mathrm{m}}\right)$ and the enthalpy of melting $\left(\Delta H_{\mathrm{m}}\right)$, calculated from the DSC curves in Fig. 1, are given in Table 5. At temperatures higher than $40^{\circ} \mathrm{C}$, different behaviours for the two copolymers are observed depending on the compatibility between the vinyl acetate and ethylene blocks. For EVA12, there is only one peak in the DSC curve, showing one phase that melts at $99^{\circ} \mathrm{C}$ (Table 5). The low amount of polar VA in EVA12 is miscible with the predominant non-polar fraction of PE. But when the amount of the polar component, VA, increases up to $20 \mathrm{wt} \%$, there are three peaks, showing the presence of three phases: the melting of the VA segments appears at lower temperature, followed by a split peak at higher temperature, corresponding to the $\mathrm{VA}+\mathrm{PE}$, and a third peak at higher temperature corresponding to the PE phase.

\subsection{Surface modifications of EVAs by plasma treatment}

To evaluate the differences in wettability (and surface energy) produced by plasma treatment (Ar, $\mathrm{N}_{2}$, Air, $\left(4 \mathrm{~N}_{2}: 6 \mathrm{O}_{2}\right)$ mixture, $\mathrm{O}_{2}$ and $\left.\mathrm{CO}_{2}\right)$, the advancing contact angles between EVA specimens and bidistilled water as test liquid were obtained. The advancing contact angles at $25^{\circ} \mathrm{C}$ given in Fig. 2, show that the values obtained 


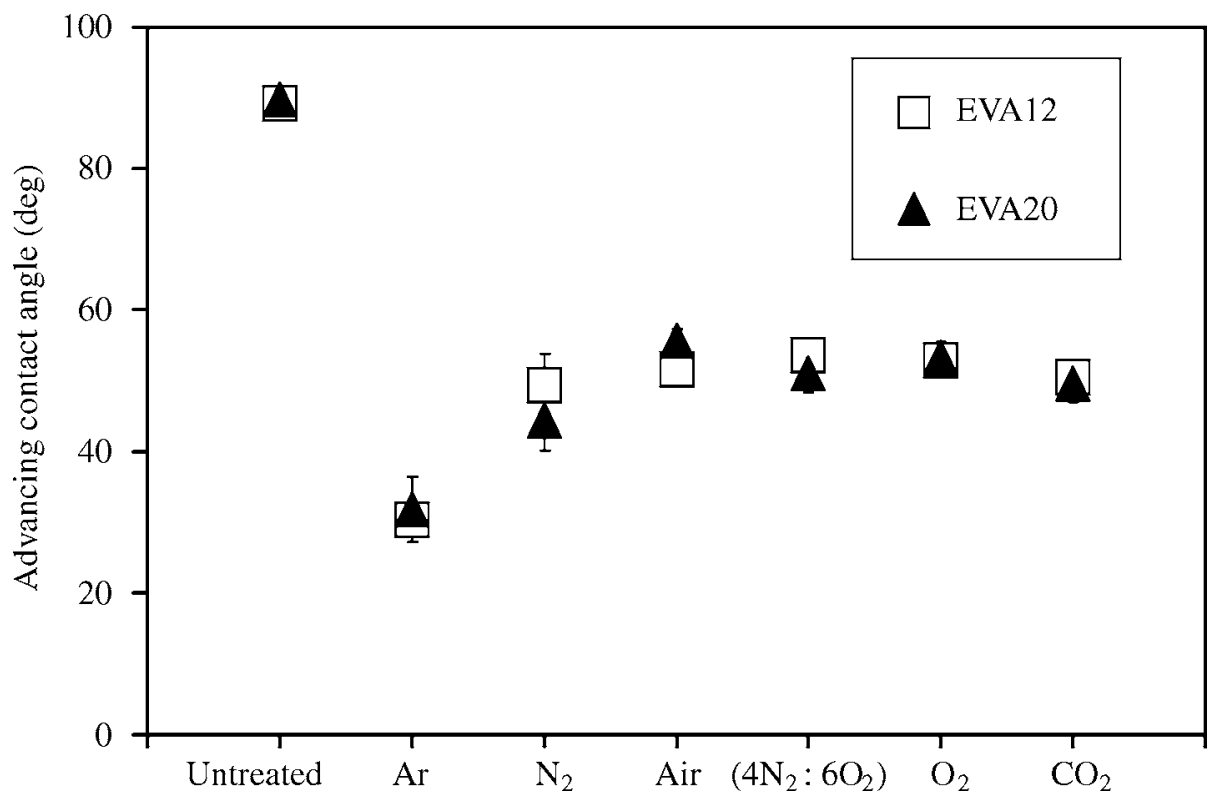

Figure 2. Advancing contact angles values (water at $25^{\circ} \mathrm{C}$ ) for EVA12 and EVA20 surfaces treated with RF plasmas from different gases.

for treated EVA12 and EVA20 with all plasmas are quite similar, independent of the VA composition, indicating that the composition of EVA copolymers, basically of hydrophobic nature, does not seem to affect greatly the wettability resulting from the plasma treatment. A more noticeable feature is the lowering of contact angles from the untreated material to the treated sample with all plasmas, showing that the improvement in wettability produced by plasma in the treated surfaces depends on the reactivity of the gas used to obtain the plasma. The trend of the lowering in contact angles seems to be related to the reactivity of the plasma, the lower the reactivity, the lower the contact angle values, i.e. the higher the wettability of the treated surface by water. This is the case for Ar and $\mathrm{N}_{2}$ plasmas, for which it has been found elsewhere $[6,16]$ that in polymers treated with these plasmas, the amounts of oxygen and nitrogen groups at the surface are enhanced.

To assess the chemical composition at the surfaces of the untreated and plasma treated EVA copolymers, the XPS spectra were obtained. The atomic percentages of elements are shown in Table 6, together with the corresponding $\mathrm{O} / \mathrm{C}$ ratios, showing that the carbon content of the untreated copolymers is higher in EVA12 than in EVA20, and the oxygen content is lower, as it was expected from their compositions. Additionally, a small silicon peak appears in each spectrum which is suspected to be a contaminant because there are no silicon compounds in the formulations, or processing, of the copolymers used in this study. From the analysis of the variation of oxygen content as a function of the gas used to obtain the plasma, the surface composition is in agreement with the scission of VA chains and 


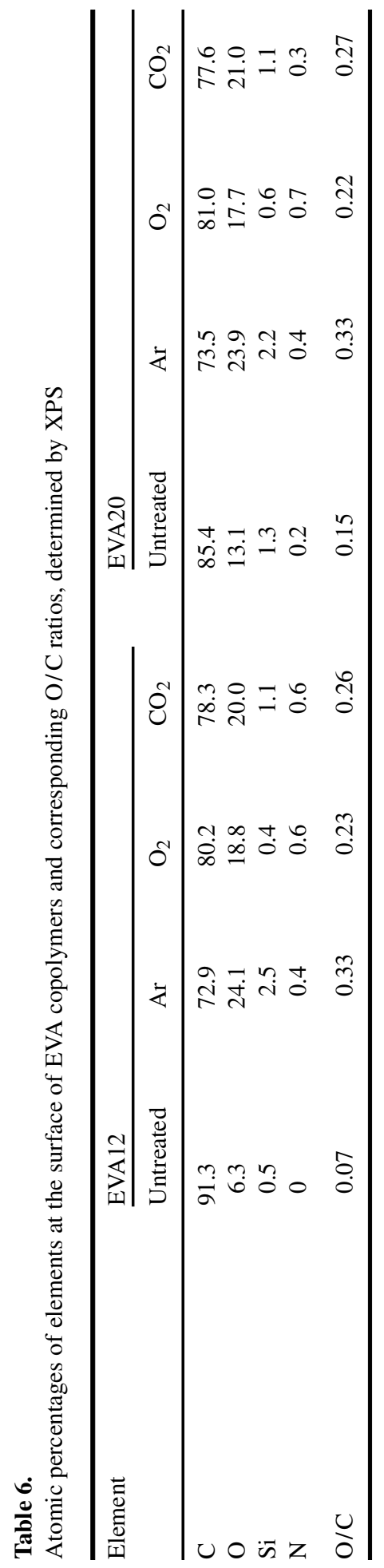


cross-linking of PE chains produced in the two copolymers after treatment with the different plasmas. The lowering in carbon content is higher with the plasmas of nonoxidizing gases and is quite similar for both copolymers showing that the VA chain scission is produced. On the other hand, the oxygen atomic percentage increases as the carbon content of VA decreases (scission processes under non-oxidizing plasma treatment are produced in this polymer). Thus, the oxygen functionalities at the surface increased after plasma treatment in both copolymers as shown in Table 6 . With respect to the copolymers treated with oxidizing plasmas, the oxidation results in strong ablation of the surface, the atomic percentage of oxygen is increased, but to a lesser extent than in the case of non-oxidizing gases.

The nature of the oxygen functionalities created by the different plasmas in the carbon skeleton of the two EVAs was assessed from the corresponding curve fitting of the C1s photopeaks from the XPS spectra (Fig. 3 and Table 7). According to Fig. 3 and Table 7, for the untreated copolymers, EVA12 and 20, the curve fitting yields a common spectrum with a main peak at $285.0 \mathrm{eV}[\mathrm{C}-\mathrm{H}, \mathrm{C}-\mathrm{C}]$, one peak corresponding to carbon not bonded directly to oxygen at $285.8 \mathrm{eV}$ $\left[\mathrm{C}^{*} \mathrm{H}_{3}-(\mathrm{C}=\mathrm{O})-\mathrm{O}\right]$, and other two peaks corresponding to $\mathrm{C}$ bonded to oxygen at $286.9\left[\mathrm{C}^{*} \mathrm{H}-\mathrm{O}-(\mathrm{C}=\mathrm{O})\right]$ and $289.5 \mathrm{eV}\left[-\left(\mathrm{C}^{*}=\mathrm{O}\right)-\mathrm{O}\right]$. In both surface treated copolymers with plasmas, the three peaks, corresponding to $\mathrm{C}$ bonded directly or indirectly to oxygen, are split into four peaks at binding energies of 285.7 [ $\mathrm{C}^{*}-\mathrm{CO}$, $\mathrm{C}-\mathrm{N}], 286.8[\mathrm{C}-\mathrm{O}], 288.0[\mathrm{C}=\mathrm{O}, \mathrm{NH}]$ and $289.5 \mathrm{eV}$, the most important of these being that at $285.7 \mathrm{eV}$ in both EVAs treated with $\mathrm{CO}_{2}$ plasma, and the second in intensity, the peak at $286.8 \mathrm{eV}$, is more noticeable for both EVAs treated with Ar plasma.

The morphology of the untreated and treated EVA surfaces were assessed from SEM pictures (Fig. 4). The surface of EVA12 treated with all plasmas, nonoxidizing and oxidizing, shows less differences than that of EVA20 because of the more homogeneous composition of EVA12 than EVA20, as deduced from the DSC analysis in Fig. 1. The roughness developed at the surface of EVA20 by nonoxidizing plasmas is noticeable due to chain scission of VA and cross-linking in $\mathrm{PE}$, in contrast to the oxidizing plasmas that produced strong ablation of both VA and PE, leaving a more homogeneous surface. Some cracks are shown on surfaces treated with oxygen plasma, indicating that, during this treatment, the temperature at the surface had risen by the strong oxidizing reaction. A less oxidizing reaction with $\mathrm{CO}_{2}$ does not produce cracks at the surface, but only ablation.

To assess the consequences all of these changes produced at the surfaces of the EVA copolymers on their adhesion properties, Fig. 5 shows the peel strength values obtained for untreated and plasma treated EVA/polyurethane adhesive joints before and after ageing. As expected from the non-polar nature of EVA, i.e. the absence of polar groups at the surface, the peel strength values for adhesive joints with untreated EVAs are negligible. The treatment with non-oxidizing plasmas $\left(\mathrm{Ar}, \mathrm{N}_{2}\right)$ gives rise to an increase in peel strength values but not as high as expected according to the enhancement of the surface polar moieties (Tables 6 and 7) and wettability 


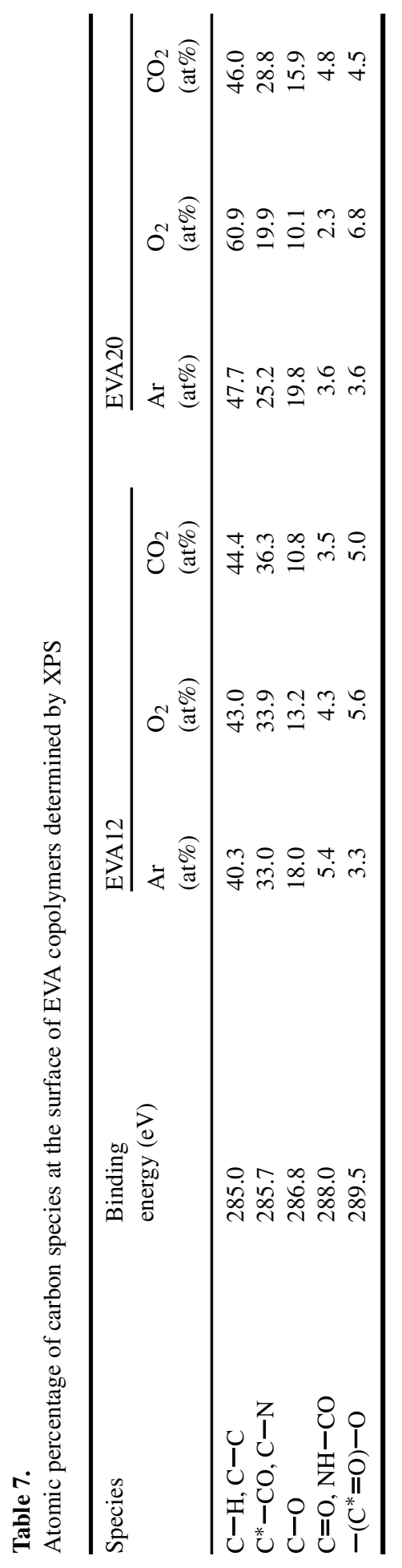



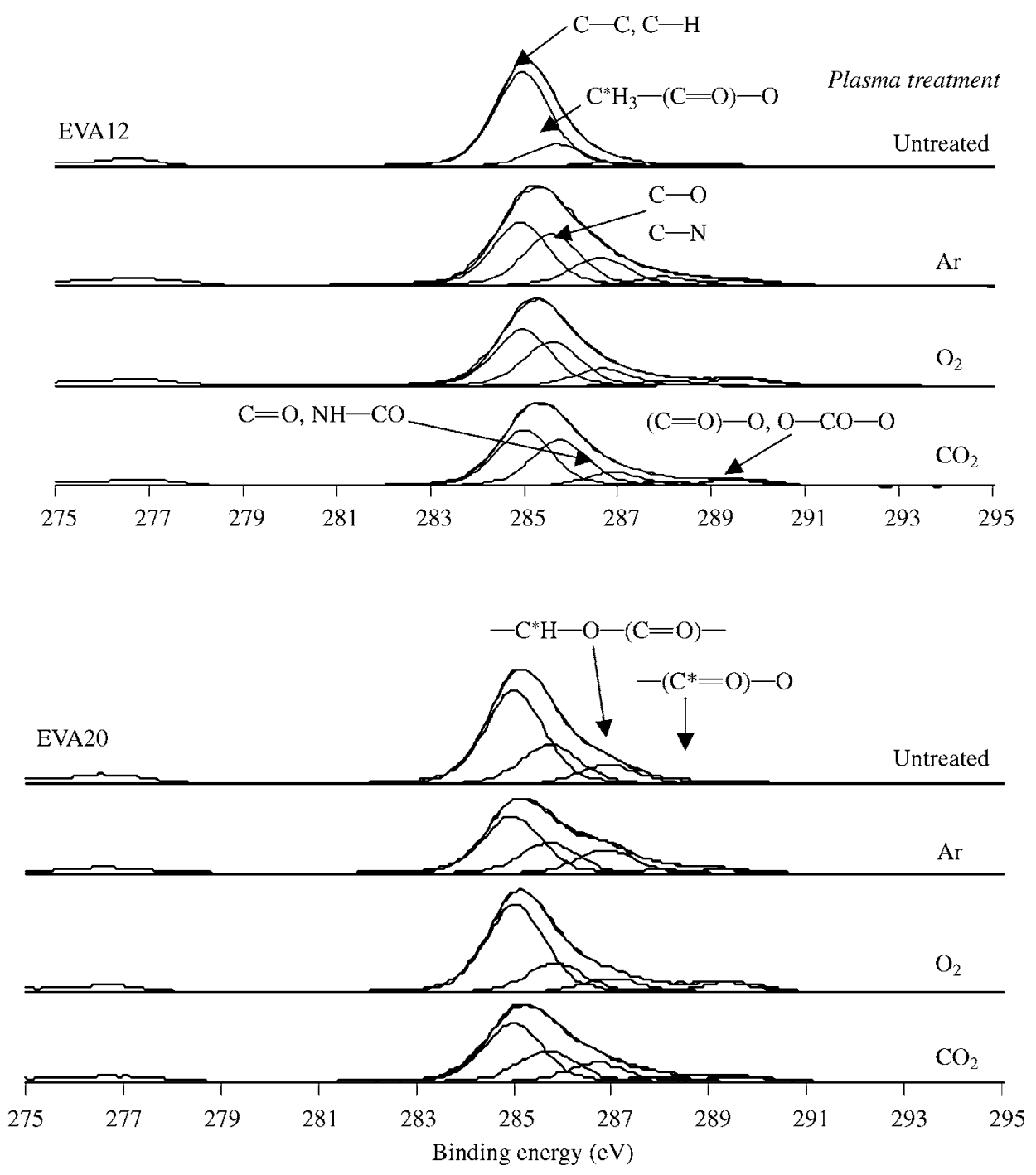

Figure 3. Curve fitting of C1s photopeaks of the XPS spectra of EVA copolymers.

(Fig. 2). For plasmas of oxidizing gases (Air, $\left(4 \mathrm{~N}_{2}: 6 \mathrm{O}_{2}\right)$ mixture, $\mathrm{O}_{2}$ and $\mathrm{CO}_{2}$ ), there is a higher enhancement of peel strength values than for non-oxidizing gases and, because the wettability (Fig. 2) and surface chemistry (Table 6) are in these cases less improved, it seems that the adhesion could be determined by other factors different than wettability and surface chemistry. Mechanical adhesion could likely result in a better adhesion performance of EVAs treated with plasmas of oxidizing gases (according to the differences in roughness shown in Fig. 4), but this aspect needs further studies to obtain more definitive conclusions. 


\section{Plasma treatment}

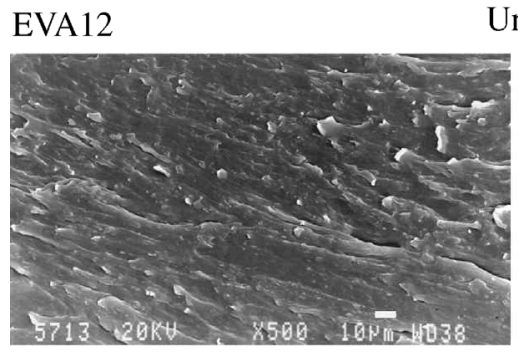

Untreated

EVA20

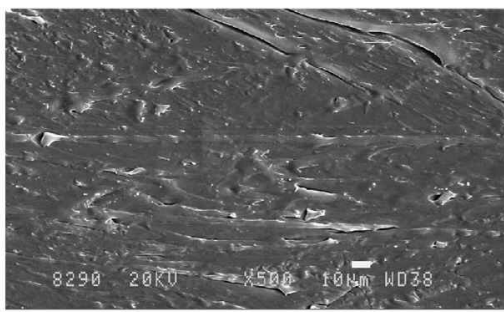

$\mathrm{Ar}$
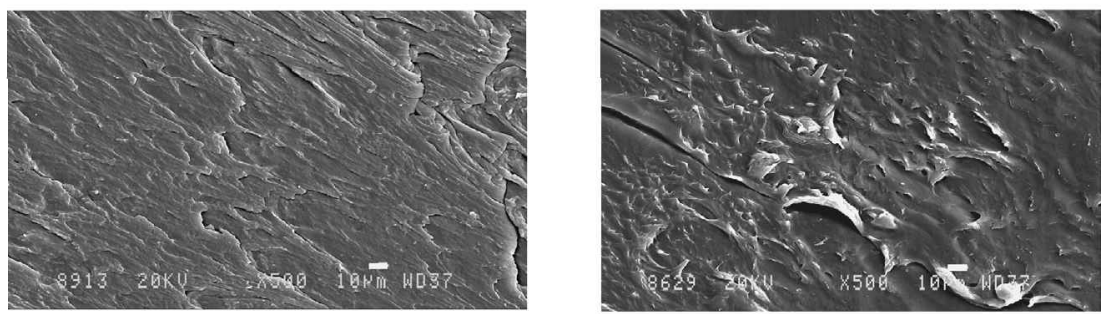

$\mathrm{O}_{2}$
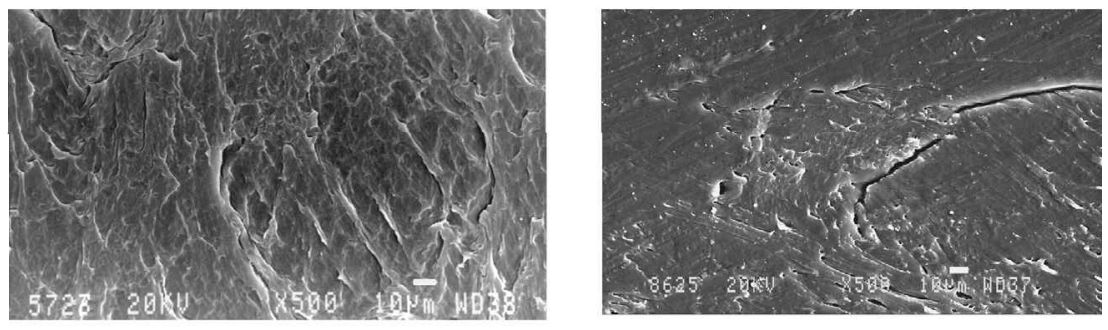

$\mathrm{CO}_{2}$
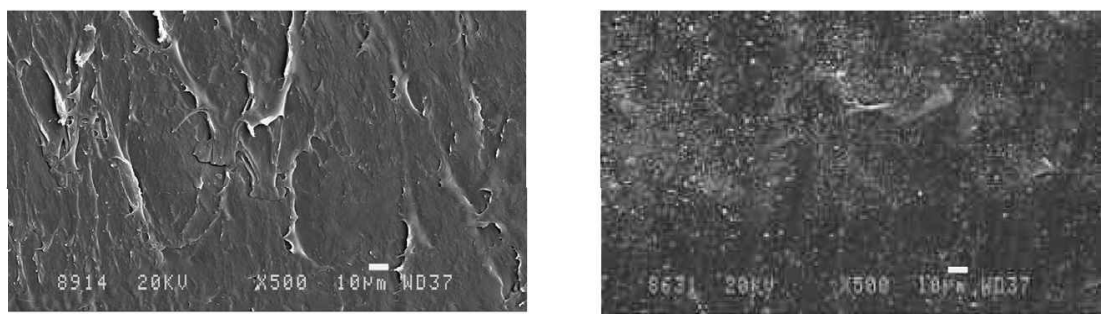

Figure 4. SEM micrographs of untreated and plasma treated EVA12 and EVA20.

The peel strength of treated EVA/polyurethane adhesive joints decreases after ageing at $95 \%$ relative humidity and $50^{\circ} \mathrm{C}$ for $72 \mathrm{~h}$ (Fig. 5). The decrease is somewhat more marked for the joints produced with EVA12 and the durability of the joints is greater in EVAs treated with oxidizing plasmas. 


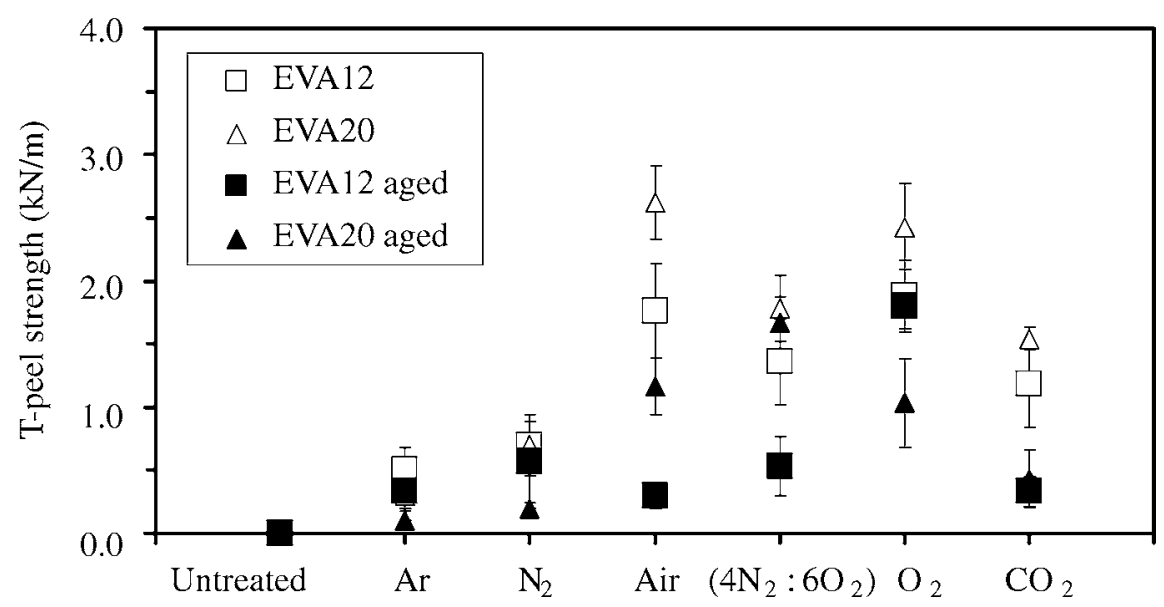

Figure 5. T-peel strength values of untreated and plasma treated EVA/polyurethane adhesive joints before and after ageing $\left(50^{\circ} \mathrm{C}\right.$ and $95 \%$ relative humidity for $\left.72 \mathrm{~h}\right)$.

\section{CONCLUSIONS}

Treatment with plasmas from different gases enhanced the wettability, by introducing $\mathrm{C}-\mathrm{O}$ and $\mathrm{C}=\mathrm{O}$ moieties, and increased the roughness at the surface of EVA copolymers containing 12 or $20 \mathrm{wt} \%$ vinyl acetate. Although the surface polar moieties of the untreated EVA12 and EVA20 were different, similar wettability and chemical composition at the surfaces were obtained for the two copolymers after all plasma treatments. The peel strength values of plasma treated EVA/polyurethane adhesive joints increased when the EVAs were treated with oxidizing plasmas, this is in agreement with the enhancement of the mechanical component of the adhesion force produced by the treatment. However, in spite of the fact that the wettability and chemical polar moieties were enhanced by plasma treatment, EVAs treated with non-oxidizing plasmas showed low peel strength, likely due to reduced mechanical adhesion.

\section{Acknowledgements}

Financial support from the Spanish Research Agency CICYT (MAT98/0611) is gratefully acknowledged.

\section{REFERENCES}

1. R. Wegman, in: Surface Preparation Techniques for Adhesive Bonding, p. 116. Noyes Publications, Park Ridge, New Jersey (1989).

2. J. Mort and J. Jansen (Eds), Plasma Deposited Thin Films. CRC Press, Boca Raton, FL (1986).

3. D. M. Manos and D. L. Flamn (Eds), Plasma Etching, An Introduction. Academic Press, Boston (1990).

4. R. d'Agostino (Ed.), Plasma Deposition, Treatment and Etching of Polymers. Academic Press, Boston (1990). 
5. D. Li and J. Zhao, in: Polymer Surface Modification: Relevance to Adhesion, K. L. Mittal (Ed.), pp. 137-149. VSP, Utrecht, The Netherlands (1996).

6. F. J. Holly and M. J. Owen, in: Physicochemical Aspects of Polymer Surfaces, K. L. Mittal (Ed.), Vol. 2, pp. 625-636. Plenum Press, New York (1983).

7. M. J. Owen and P. J. Smith, in: Polymer Surface Modification: Relevance to Adhesion, K. L. Mittal (Ed.), pp. 3-15. VSP, Utrecht, The Netherlands (1996).

8. N. Inagaki: Plasma Surface Modifications and Plasma Polymerization. Technomic, Lancaster, PA (1996).

9. M. D. Landete-Ruiz, J. A. Martínez-Diez, M. A. Rodríguez-Pérez, J. A. De Saja and J. M. Martín-Martínez, J. Adhesion Sci. Technol. 16, 1073 (2002).

10. C. M. Cepeda-Jiménez, M. M. Pastor-Blas and J. M. Martín-Martínez, in: Proceedings of the 23rd Annual Meeting of the Adhesion Society, Hilton Head, SC, pp. 83-85 (2000).

11. D. Klein, E. Tomasella, V. Labed, C. Meunier, Ph. Cetier, M. C. Robe and A. Chambaudet, Nucl. Instrum. Methods in Phys. Res. B 131, 392 (1997).

12. On-line National Institute of Standards and Technology, NIST, Atomic Spectra Database: http://physics.nist.gov/cgi-bin/AtData/main_asd

13. E. E. Kundardt and L. H. Luessen, in: Electrical Breakdown and Discharge in Gases, Fundamental Processes and Breakdown, p. 395. Plenum Press, New York (1981).

14. A. Chapiro, J. Polym. Sci. 29, 231 (1958); 30, 439 (1959).

15. G. Beamson and D. Briggs, High Resolution XPS of Organic Polymers. The Scienta ESCA 300 Database. John Wiley \& Sons, New York (1992).

16. M. Charbonnier, M. Romand, M. Alami and T. M. Duc, in: Polymer Surface Modification: Relevance to Adhesion, K. L. Mittal (Ed.), Vol. 2, pp. 3-27. VSP, Utrecht, The Netherlands (2000). 